\title{
NOTAS MARGINALES SOBRE LA EDUCACION PREESCOLAR EN COLOMBIA
}

Hugo Cerda G.*

\section{A modo de preámbulo}

No decimos nada nuevo si afirmamos que en el diseño, planeamiento y realización de un proceso educativo tienen una importancia fundamental las bases y los puntos de sustentación teórica en donde se asienta este proceso. Estos presupuestos teóricos nos señalan el camino que se debe elegir en cada caso, las relaciones entre las distintas variables que influyen en el hecho educativo, los fenómenos, objetos y procesos relacionados con el hecho de aprender y enseñar, así como las relaciones empíricas que pueden establecerse entre ellos y los recursos e instrumentos con los cuales se ha de trabajar. Con ello estamos señalando los niveles de significación que poseen los modelos estructurales, los patrones generales y una filosofía que oficie de columna vertebral y que sirva de sustrato al proceso educativo. Pero la teoría no solo generaliza la experiencia práctica, sino que va mucho más lejos, descubre los nuevos vínculos, los aspectos del objeto y con ello contribuye a que la práctica lo domine con más éxito. —De ahí la importancia que tiene para la educación el contar con una base teórica que le sirva de apoyo y de fundamento-.

Sabemos lo difícil que es para cualquier nivel educativo alcanzar un crecimiento cualitativo o cuantitativo superior, si no tiene como referente inmediato o mediato una filosofía que incluya los conceptos y los fundamentos más generales sobre la forma y desarrollo de un proceso educativo en relación a las necesidades básicas de un medio social determinado. O sea un basamento teórico que de hecho se constituya en una auténtica concepción sobre la praxis educativa y sobre la realidad donde actúa. Sin estas premisas básicas, cualquier instancia educativa corre el peligro de convertirse en una suma de remiendos, de métodos, técnicas y normas burocráticas sin un propósito definido, que procuran satisfacer una necesidad inmediata y que se agota en el instante en que esta necesidad es satisfecha.

Todos estos postulados señalados para la educación en general, tienen plena vigencia en el tema que nos ocupa: La Educación Preescolar Colombiana, la cual, aunque se le ha reconocido algunas características propias, no escapa a ese desmembramiento e, inclusive, a esa incoherencia que se observa en el sistema educativo en su totalidad y cuyos orígenes los encontramos, precisamente en la ausencia de una filosofía directriz que señale sus objetivos, determine sus áreas de actuación y coordine los medios que se emplearán. $Y$ el problema se torna aún más agudo en la educación preescolar, si se piensa en una serie de factores que de hecho han convertido a este nivel educativo en un proceso marginal, segregado, no plenamente aceptado por algunos sectores y cuyo carácter opcional la han transformado en un concepto vago, cuya pluralidad de funciones escapan a cualquier orden vigente en el sistema educativo.

\footnotetext{
* Realizó estudios en el Instituto Pedagógico, Escuela de Bellas Artes y Escuela de Teatro de la Universidad de Chile. Becono de la Academia de Artes musicales y Escénicas de Praga. Profesor de la Universidad Pedagógica Nacional.
} 
Y es precisamente este orden de cosas lo que nos ha impulsado a escribir estas notas críticas, que pretenden ocuparse de algunos problemas básicos de esta área educativa, los cuales no son ajenos a una problemática general de la educación y cuya solución necesariamente debe darse globalmente. Es obvio que estas notas no aspiran a dar soluciones enfáticas a estos problemas, sino simplemente buscan destacar y analizar las modalidades vigentes en este campo, lo cual nos ayudará a definir algunas premisas básicas que pueden ser de enorme utilidad en el instante que los docentes y las autoridades se decidan procurarle un marco teórico y conceptual a la educación preescolar en Colombia.

Este intento por coneptualizar algunos aspectos que de facto se dan en la educación preescolar, no es producto de un juicio "a priori" sobre esta realidad, sino es el resultado de numerosos estudios e investigaciones que hemos adelantado estos últimos años y que deseamos se conviertan en una verdadera apertura hacia la discusión y el debate científico sobre la problemática que nos ocupa. Estamos convencidos que la educación preescolar debe operar dentro de ciertas bases conceptuales, de lo contrario este nivel educativo seguirá siendo víctima de numerosos supuestos empíricos que buscan las soluciones por la vía inmediata y no como parte de una acción que englobe toda la educación en su conjunto. Nuestro interés fundamental radica en propiciar una discusión teórica a nivel profesional y científico, postergada y confundida en los distintos enfrentamientos metodológicos (empirismo, operacionalismo o formalismo) que se suscitan en la práctica y que han convertido la educación preescolar en una instancia que escapa a toda definición, clasificación y evaluación científica.

Porque si bien, en Colombia, la educación preescolar adolece de fallas estructurales, no podemos dejar de reconocer que ella es una realidad concreta. Existen cientos de guarderías y jardines infantiles en todo el país, una legislación sobre sus programas y sistemas administrativos, normas que rigen su funcionamiento, universidades y centros académicos que forman docentes en esta área, etc. Podemos realizar duras críticas a la anarquía, mercantilismo, bajo nivel académico de sus programas y de sus docentes y a otros aspectos medulares de su régimen pedagógico o administrativo, pero no podemos dejar de reconocer que la educación preescolar ha tenido un importante incremento cuantitativo estos últimos años, aunque no en la medida de las exigencias y necesidades nacionales. Sí ponemos en tela de juicio sus fallas y sus vacíos estructurales, es porque ella se ha convertido en una realidad tangible, cuyo desarrollo, más que inevitable, es fundamental en la formación del niño. De ahí nuestro interés por plantear sus problemas en forma franca, directa y sin aufemismos de ninguna naturaleza.

En la actualidad, en Colombia, los conceptos "escuela maternal", "educación temprana", "atención integral", "aprestamiento", "educación compensatoria" y otras acepciones análogas, se han transformado en los denominadores centrales de un problema que desgraciadamente solo parece inquietar a un pequeño grupo de especialistas, a pesar de que ello afecta o se conexiona directamente con el $25 \%$ de la población colombiana, o sea el total de personas menores de 7 años. $Y$ aunque la cobertura nacional de la educación preescolar es muy baja, su acelerado ritmo de crecimiento en estos últimos años ha sobrepasado con creces toda medida de control, supervisión y planificación por parte de los organismos responsables de esta área educativa ${ }^{22}$.

\footnotetext{
${ }^{22}$ Según el DANE, en el periodo comprendido entre 1967 y 1975, la Educación Preescolar demuestra una tendencia creciente de $81.69 \%$ en la matrícula o sea una tasa media anual de $9.07 \%$. En lo que respecta a los docentes en preescolar, aumentan de 2.252 en 1967 a 3.855 en 1975, con una tendencia creciente de $58.44 \%$ para el periodo $1967-75$ y una tasa media anual de $6.49 \%$. La participación de los profesores del sector oficial es de $74.64 \%$ comparada con el oficial que es de $25.36 \%$. En este mismo período el Digitalizado por RED ACADEMICA
} 
Para algunos educadores, aquello de "acelerado ritmo de crecimiento" puede prestarse a engaño, ya que el déficit en este terreno es dramático, debido a la elevada tasa de crecimiento de la población colombiana y al aumento de las necesidades en este rubro a causa de la crisis socio-económica que enfrenta la familia colombiana de bajos ingresos. Para medir este déficit, basta observar el siguiente cuadro porcentual de la educación preescolar en Colombia.

La extensión del problema es aún superior si se piensa en las ramificaciones de tipo socio-económico, educativas, culturales, sicosociales y políticas que han derivado en torno a la necesidad de asistir, cuidar y educar al niño desde su más tierna edad.

\section{CUADRO PORCEPTUAL DE LA EDUCACION PREESCOLAR EN COLOMBIA - 1976}

$\begin{array}{ll}\text { Población total de niños en edad preescolar } & 24.5 \\ \text { Niños atendidos por los establecimientos preescolares } & 2.0 \\ \text { Niños atendidos por los establecimientos oficiales } & 30.6 \\ \text { Niños atendidos por los establecimientos privados } & 69.4 \\ \text { Establecimientos preescolares oficiales } & 27.3 \\ \text { Establecimientos preescolares privados } & 72.7 \\ \text { Docentes en establecimientos oficiales } & 25.4 \\ \text { Docentes en establecimientos privados } & 74.6\end{array}$

Fuentes: ICFES, La Educación Preescolar en Colombia: mito o realidad. Bogotá, 1978. DANE, Boletín Mensual de Estadística, "La Educación en Colombia, 1975", Bogotá 1977.

Hace medio siglo, las nociones de "kindergarten", "jardín infantil", etc., eran prácticamente desconocidas en el Continente y en Colombia, aunque ya existían algunos establecimientos que cuidaban y recibían niños menores de 7 años, no cumplían funciones educativas propiamente tales. Eran en su mayoría hospicios o casas-asilos para niños abandonados, dirigidas por órdenes religiosas o por el Estado, que por razones humanitarias eran atendidos y asistidos sin un propósito educativo definido, salvo la solución de algunas necesidades inmediatas que la institución debía satisfacer esporádicamente. Sus móviles no se diferenciaban de los que impulsaron a Robert Owen a fundar los asilos para niños de las obreras de la hilandería de New Lanark o los promovidos por Oberlin en 1769, con destino semejante. En general, eran instituciones que buscaban mitigar la miseria y curar las heridas sociales de las masas desposeídas que iba dejando como saldo la Revolución Industrial, el desarrollo urbano, la inmigración campesina a la ciudad, el desempleo, etc. Era un subproducto de las primeras etapas de la industrialización capitalista y que por diversas causas aún perdura en nuestros días, aunque con características diferentes.

\footnotetext{
incremento de los establecimientos preescolares es de $49.60 \%$, lo cual equivale a una tasa media anual de crecimiento del 5.5\%. Es notable el aumento en el promedio de alumnos por establecimiento: en 1967 era de 43 y en 1975 aumenté a 52. Aunque las cifras del DANE son poco confiables debido al gran número de jardines ilegales que existen en el país, ellas nos ponen de manifiesto el importante crecimiento que ha tenido la Educación Preescolar en este período. (FUENTE: DANE, Boletín Mensual de Estadística, 'la educación en Colombia, 1975”, Bogotá, 1977).
} 
Las corrientes renovadoras que invadieron la pedagogía y la psicología de nuestro siglo, hicieron posible la incorporación de nuevos conceptos en el campo educativo y contribuyeron a modificar los criterios asistencialistas que dominaban este terreno. Surgió el concepto de "educación temprana o preescolar", el cual, evaluado por los numerosos estudios realizados sobre la sicología y el desarrollo infantil, planteaba como premisa fundamental la necesidad de atender algunos requerimientos básicos en los primeros años de vida del niño, con el propósito de asegurar el desarrollo físico, intelectual, social y afectivo de sus etapas posteriores. Los aportes científicos realizados por Froebel, Montessori, Rosa Agazzi, Decroly y otros pedagogos, fueron definitivos en la estructuración de los sistemas y métodos pedagógicos que buscaban definir una etapa de aprestamiento preescolar y que de hecho se constituía en la antesala de la escuela.

Pero desde que Federico Froebel desarrolló sus métodos e ideas sobre la pedagogía de la edad temprana hasta nuestros días, se han producido numerosos cambios en los modelos metodológicos y orientaciones educativas, en tal grado, que hoy día los especialistas ya nos hablan de una concepción "moderna" y otra "tradicional" de la educación preescolar. Aunque esta categorización formalista tenía una implicancia puramente pedagógica, no hay duda que ella tiene el mérito de reflejar los profundos cambios que se observan en el terreno social, político, económico, cultural y tecnológico de nuestro siglo. Para estos especialistas, los métodos "clásicos o tradicionalistas" se caracterizaban por un autoritarismo casi represivo, cuyas metas ideales eran el orden, la obediencia, la disciplina, el aprendizaje memorístico, el conformismo y otras instancias normativas propias de la escuela tradicional, de la cual heredó la educación preescolar sus orientaciones fundamentales. La extrema rigidez de sus métodos $y$. de sus programas, las relaciones de dependencia casi absoluta del niño frente a la maestra, la pasividad y acriticidad que promovían sus métodos, no compaginaban con los nuevos postulados pedagógicos que hacían énfasis en los valores de la creatividad, de la espontaneidad, de la participación activa, de la iniciativa individual, de la actividad colectiva y de la libre expresión del niño. Estos métodos "modernos", eran una concepción pedagógica más dinámica y flexible, mejor adaptada a las necesidades del niño y abierta a todas las corrientes educativas contemporáneas y a los valiosos aportes de la sicología, antropología social, medicina, sociología, etc. Si bien ambas concepciones tenían como punto de convergencia el proceso de enseñanza-aprendizaje desarrollado en la escuela, las formas de abordarlo y resolverlo eran completamente diferentes.

\section{El concepto “integralista” en la educación preescolar}

Aunque estas vertientes históricas de la pedagogía preescolar tenían como patrón único el niño como individuo, en sus directrices fundamentales no se consideraban los imponderables socio-económicos, culturales y nutricionales de ese niño que debía incorporarse a la institución preescolar. El "antes" era una categoría que se traspasaba a la familia, al medio social ya la comunidad, pero no le correspondía a la entidad educativa. En general, se hacía referencia al niño como individuo y en última instancia al medio donde vive, olvidando que en ese contexto socio-económico donde habita y se desarrolla se dan las premisas básicas de su desarrollo.

A la luz de los movimientos sociales y políticos de nuestra época que reivindicaron el derecho de las masas populares a la educación, a la salud, a la cultura, al trabajo y a los beneficios sociales que les corresponden a todo ser humano, surgieron numerosas estrategias que apuntaban hacia la solución de una serie de problemas, que de hecho eran la caja de resonancia política e ideológica de los conflictos sociales que se suscitan en el sistema. Se comenzó a hablar de educación masiva, popular, compensatoria, 
democrática, abierta a todos los grupos sociales y étnicos, con lo cual se pretendía hacer de la educación el instrumento que ilusoriamente iba a contribuir a establecer una sociedad más igualitaria. "No es producto de un puro altruismo el que las naciones industrializadas y modernizadas hayan llevado a cabo amplios sistemas de enseñanza para la "instrucción" de las masas, sino para satisfacer necesidades de que exista una fuerza de trabajo más ilustrada y competente" ${ }^{23}$, afirma un informe realizado por la Fundación Bernard Van Leer, organización internacional especializada en educación preescolar y que en 1976 realizó un estudio sobre esta área en Colombia.

Numerosos factores se sumaron para dar nacimiento a una nueva estrategia "integracionista o integral" en la educación preescolar, que en teoría pretendía articular lo individual con lo social, lo físico con lo sicológico, lo potencial con lo real, los mecanismos externos con los internos y en fin, procurar servicios y desarrollar métodos de trabajo que contribuyeran a hacer del niño, no una pluralidad indiferenciada de fenómenos y conductas, sino un proceso unitario. A partir de los estudios e investigaciones realizadas por algunos neurólogos, sicofisiólogos, sociólogos y pediatras, se comenzó a aceptar la incidencia que tenía la malnutrición y la privación socio-afectiva e intelectual durante los primeros años de vida y se planteé la necesidad de buscar una respuesta en las propias condiciones de existencia del niño o sea su grupo social y familiar. Por primera vez se puso en tela de juicio aquello que se planteaba como una "desigualdad de capacidades" y que de hecho se constituyó en una "desigualdad de oportunidades", que a su vez se explicaba a partir de las relaciones existentes entre el medio físico y social del niño, su estado de nutrición, su crecimiento y su desarrollo.

Con el concepto "integral" se buscaba asociar todo un conjunto de funciones, fenómenos y procesos que participan en el desarrollo humano y los cuales se reflejan, se interaccionan y se integran en un proceso continuo, dinámico, estructurado e irreversible que solo va a culminar en la edad adulta. Es evidente que esta visión socio-sicogenética del ser humano se tradujo en términos de métodos y sistemas pedagógicos que pretendían enfocar y atender en forma unitaria las necesidades básicas de los niños pertenecientes a familias de bajos recursos económicos, con problemas nutricionales, socio-culturales y con deprivación socio-afectiva, todo ello como reflejo de las condiciones ambientales y familiares propias de su medio.

En Colombia, esta concepción integralista encontré eco en la acción y en la política desarrollada por el Instituto Colombiano de Bienestar Familiar (ICBF) y en el espíritu de la Ley 27, a pesar de que ella no es muy explícita en este sentido, ya que su visión funcionalista e instrumental deja de entrever los resabios asistencialistas de una filosofía y una praxis paliativa y paternalista que busca satisfacer "desde fuera" una necesidad determinada, independientemente de las causas que la determinan y de las consecuencias proyectistas que tiene esta asistencia para el beneficiario. Según esta ley, "la atención integral al preescolar, es el conjunto coherente de acciones que en forma directa e indirecta se realizan a través de un Centro de Atención Integral al Preescolar (CAIP) (Hogar Infantil) con el fin de contribuir al adecuado crecimiento y desarrollo del niño menor de siete años, en los aspectos físico, psíquico y social. Estas acciones, además de la atención al niño, deberán abarcar actividades formativas e informativas con la familia y de proyección a la comunidad". En general, esta ley define unos propósitos, precisa las áreas que va a atender, el ámbito donde va a actuar y las acciones que va a cumplir para alcanzar estas metas, pero desgraciadamente deja en la penumbra una serie de

\footnotetext{
23 Fundación Bernard Van Leer, Misión sobre educación infantil temprana. Informe. La Haya, Holanda,
} 1976. 
interrogantes sobre la naturaleza, contenidos y proyecciones de esta "atención integral". La ley define el concepto "integral" en términos de servicios y de acciones, pero se advierte la ausencia de una filosofía vertebradora que responda una serie de dudas sobre el papel de la provisión educativa, sobre sus conexiones con la escuela o la educación formal, sobre el futuro de aquel niño que abandona el CAIP, sobre la realidad social, sicológica y económica de aquella masa infantil a la cual se le suspende estos servicios cuando cumple los 7 años y numerosos otros problemas que no han sido claramente definidos por la Ley 27 y el ICBF. Como es de todos conocido, el ICBF, desde sus inicios ha contado con un enorme caudal de recursos económicos para llevar a la práctica estas acciones, todos ellos provenientes del $2 \%$ que está autorizado para percibir de las nóminas mensuales de todos los salarios que la empresa privada paga a sus trabajadores. Y a pesar de la gran cantidad de recursos que se destina y al abundante personal que disponen sus servicios, el balance es muy poco halagador. Numerosas entidades privadas y oficiales han realizado duras críticas al ICBF y los cargos van desde ambigüedad en su política vigente hasta la mala utilización o inversión de los fondos provenientes de la Ley $27^{24}$.

Las dudas que surgen y las preguntas que se hacen sobre los alcances del concepto "integral", no son propiamente de naturaleza semántica, sino que ellas han surgido a partir del diagnóstico y el análisis realizado por algunas instituciones y pedagogos sobre la labor realizada por el ICBF en el campo preescolar y cuya cobertura total es muy baja. Sus esfuerzos y sus recursos, desgraciadamente han sido orientados muy unilateralmente, ya que en los sectores populares donde actúa, sus servicios solo procuran aliviar temporalmente un síntoma, un problema o una necesidad y que al suspenderse, produce consecuencias regresivas a la población que atiende. Lamentablemente no existen investigaciones sobre la vida del niño después que ha hecho abandono del CAIP o de sus niveles progresivos en posteriores etapas de desarrollo, lo cual permitiría evaluar mejor la acción y los alcances del servicio preescolar que se proporciona. Pero a pesar de que no existen estos estudios, se perciben los desajustes y los problemas que acarrea para el niño y su familia, cuando por razones de edad, se le suspende el servicio. Este niño, perteneciente a familias de escasos recursos económicos, que en el CAIP se le procura

\footnotetext{
${ }^{24}$ Existe confusión sobre la actual cobertura y el número de CAIP que existen en el país, ya que el régimen administrativo y jurídico que regula estos establecimientos, era hasta hace unos meses, poco claro, existiendo dudas sobre el verdadero régimen de propiedad de algunos jardines, los cuales se repetían en la listas del ICBF y los gobiernos departamentales, intendenciales y comisariales. El ICBF asesora, financia, promueve y organiza jardines, pero en la mayoría de los casos no se encarga de la administración directa de estos centros, salvo aquellos centros pilotos que dependen de sus Regionales y que se encuentran ubicados en las cabeceras de los departamentos. Solo recién, en julio de 1977, mediante el Decreto No. 1617, se establecieron normas orgánicas sobre la organización, bienes y régimen jurídico de los CAIP y sus relaciones con el ICBF. Según el Consolidado de Programación aprobado para el Programa de Atención Integral al Preescolar (enero 1976-junio 1977) se había aprobado el funcionamiento de 508 CAIP con una cobertura de 46.214, pero hasta esa fecha se encontraban funcionando 249 CAIP que atendían 20.057 niños en edad preescolar. Pero el hecho más controvertido que se suscité en torno al ICBF, fue cuando su ex-director, Dr. Antonio Ordóñez Plaja, en una entrevista realizada al periódico "El Tiempo", declaró por primera vez que el Programa de Atención Integral al Niño Preescolar había invertido 1500 millones en Unidades de Poder Adquisitivo Constante (UPAC) (EL TIEMPO, junio 27 de 1977, Bogotá). En un reportaje que realizó la revista capitalina GUION al ex-alcalde Dr. Bernardo Gaitán Mahecha, escribía sobre el problema suscitado: "Más de dos mil millones de pesos recaudé el ICBF durante 1975 y 1976, por concepto de dos por ciento, que esté autorizado para recibir de las nóminas mensuales de los salarios que la empresa privada paga a sus trabajadores. La destinación legal de estos recursos considerables es la atención integral de niños en edad preescolar. Curiosamente, tal suma no ha cumplido su misión y se ha convertido en un recurso financiero, en parte invertido en UPAC, en parte destinado por las autoridades monetarias a servir un papel contraccionista de los medios de pago en circulación, dadas la ineficacia operativa y la lentitud del Instituto para acometer las obras y los programas que le han sido encomendados" (GUION, No. 4, marzo 7 de 1977, Bogotá).
} 
alimentación, ropa, juguetes, atención médica y otros servicios, cuando se le suspende esta atención por un imperatico legal, debe enfrentarse a la dura realidad socioeconómica de su familia que carece de los recursos para proporcionarles servicios similares. ¿Qué consecuencias sociales y afectivas puede traer una situación de esta naturaleza? Aunque no existen estudios longitudinales sobre el asunto, no es necesario ser un especialista en la materia para darse cuenta que los efectos son imprevisibles, ya que esta frustración o desilusión pueden ser los gérmenes de una inadaptación, alienación, conducta agresiva u otros síntomas negativos para su posterior desarrollo. Para algunos siquiatras y pediatras, esta discontinuidad en los servicios que se provee a nivel social y nutricional, a la postre contribuyen a afianzar una condición de menor valía, inseguridad en el niño. En todo caso, cualquier crítica o argumento que se utilice en tal sentido, puede convertirse en un verdadero detonador sobre el problema y transformarse en un motivo de debate y de discusión en los sectores relacionados con esta área.

Pero el criterio de unilateralidad no solo se plantea en el caso anterior, sino también en el tipo de servicios que procura el ICBF. Todos sabemos que estos servicios dependen del Ministerio de Salud y ellos consideran muy tangencialmente el problema educativo, ya que por razones obvias, centran su acción en el factor salud y alimentación. En el mencionado informe de la Fundación Bernard Van Leer se destaca claramente este hecho, al señalar que "a la luz de los conocimientos subrayados sobre la intención de la Ley 27, se hizo cada vez más claro para la Misión —al evaluar las necesidades de Colombia, las prácticas presentes y los objetivos en la educación de la niñez tempranaen que el elemento educacional ha faltado en forma significativa en la mayoría de las provisiones preescolares, tanto en la intención como en la práctica. La nutrición y la legislación para la protección del niño necesitan el vehículo de la educación para su exitosa implementación. La alimentación sola no es suficiente; ni lo es una tutela legal ilustrada sobre los derechos de los niños. Los nutricionistas mismos, a través de sus propias investigaciones, han indicado que las mayores ganancias derivadas de los programas de nutrición se alcanzan solamente sí éstos son complementados con programas de educación" 25 .

Nadie pone en duda un hecho irrefutable: la niñez desnutrida, deprivada social y afectivamente, no puede alcanzar formas superiores de desarrollo y si las alcanza, lo logra en condiciones de desventaja con relación a la niñez que no tiene estos problemas. Concretamente, esta masa infantil deprivada no va poder integrarse normalmente al circuito educativo que nuestros sistemas han señalado como condición básica de todo desarrollo y formación. De ello se deduce que la "atención integral" debe darse necesariamente en términos educativos, ya que al hecho educativo le corresponde desempeñar una función cohesiva o sea será la razón integradora de todos aquellos servicios sociales, de salud y nutrición que se procuran.

Numerosos pedagogos y especialistas en educación preescolar están de acuerdo en que la "dieta educacional" no puede convertirse en un componente más de esta atención integral al niño deprivado, ya que de lo contrario esta acción se transformará "en un servicio más", el cual no tiene otro propósito que satisfacer una necesidad al igual que la nutrición y la atención médica. Con ello se está vulnerando un principio básico del desarrollo humano: la unidad de lo síquico y lo físico, de la siquis y el cerebro, que usualmente se ha planteado en términos de maduración y formación o de naturaleza y educación. Todos sabemos que ellas son facetas recíprocamente independientes entre sí, pero que se compenetran una en otra, que están contenidas en un mismo proceso, donde

\footnotetext{
${ }^{25}$ Fundación Bernard Van Leer, Misión sobre educación infantil temprana. Informe. La Haya, Holanda, 1976.
} 
causa y efecto cambian continuamente de lugares. Muchos especialistas discrepan de estos criterios y plantean en cambio que es imposible hablar de educación si no se ha resuelto el problema nutricional y social, ya que ellos son el sustrato y el asiento del desarrollo intelectual. Pero estos argumentos serán válidos en el instante que la sociedad le asegure unas condiciones de existencia "normales" al niño desde que nace y si fuera posible, desde su etapa de gestación. De ello se infiere, que la primera fase de la atención se debe centrar en la madre embarazada y culminar en los primeros meses de vida del niño.

En esta última década, las sucesivas investigaciones sobre la relación existente entre la nutrición y el desarrollo mental, ha abierto una serie de expectativas sobre las consecuencias nefastas que se derivan de la malnutrición crónica durante el periodo comúnmente llamado del "estirón" cerebral. Como el cerebro es el asiento de las facultades mentales, este periodo critico de crecimiento es decisivo para el desarrollo del niño. El Prof. Jack Tizard, en un artículo publicado en la revista "Salud Mundial", afirma que ' una desnutrición leve durante el período en que el cerebro "da el estirón", afecta el tamaño, el peso, a la estructura, al número de células y a la composición química del órgano. Esos efectos no se corrigen ulteriormente, aunque se administre al ser desnutrido una dieta suficiente y equilibrada, sino que persisten durante toda la vida. Por el contrario, si un ser está bien alimentado durante el período de desarrollo y sufre luego un período de desnutrición, los efectos sobre el cerebro serán ligeros y podrán corregirse por completo" 26 . O sea, si no se atiende y no se ponen en práctica acciones en este sentido durante el período crítico del "estirón" del cerebro, que aproximadamente se iniciaría en los últimos 3 meses de vida intrauterina y duraría hasta los 18 a 25 meses después del nacimiento. $Y$ aunque muchos científicos afirman que no hay nada definitivo en este terreno y que muchas posiciones son producto de estudios de laboratorio, no hay duda la importancia y el significado que tienen estas investigaciones en el instante de la planeación y el diseño de las políticas orientadas hacia la atención del niño preescolar.

Todos los aspectos anteriormente señalados, ponen en claro la necesidad de revaluar y redefinir el concepto "integral" en la educación preescolar, que en definitiva deberá resolverse en consonancia con las necesidades y las exigencias propias del medio. Y ello se logrará en el instante en que se comience a comprender la importancia que posee la provisión educacional como factor cohesionador de esta atención, ya que el ser humano es una totalidad que no admite fragmentaciones de ninguna naturaleza. De lo contrario, el trabajo remedial que se realice para compensar a las capas menos favorecidas de la población, será inútil, ya que apuntará en una sola dirección y de hecho se convertirá en una acción asistencialista, paliativa y paternalista. Con ello se refuerza el carácter de dependencia de las capas menos favorecidas con relación a las instituciones del sistema que procuran estos servicios. La familia es instrumentalizada para pedir o aceptar los recursos disponibles y los mecanismos de poder del sistema afianzan aún más sus dispositivos de dominación y de autoridad.

De ahí que muchos sectores recomienden que el ICBF debe centrar su acción social y nutricional en la mujer embarazada y en los primeros meses de vida del niño y de esta manera, permitir que el niño deprivado inicie en condiciones normales la carrera en pos hacia metas educativas y de desarrollo superior. Naturalmente se parte del supuesto que el niño podrá contar con los recursos necesarios para incorporarse a la escuela, porque de lo contrario no se justifica plantear ilusoriamente estos antecedentes del desarrollo humano, si en la práctica es imposible cumplirlos, dado el carácter discriminatorio y

\footnotetext{
${ }^{26}$ Organización mundial de la salud, Revista Salud Mundial, No. 15, abril 1974, Ginebra.

Digitalizado por RED ACADEMICA
} 
clasista de nuestros sistemas educativos. En todo caso es fundamental la existencia de una concepción de desarrollo para la educación preescolar, ya que ello posibilitará la articulación de los niveles de madurez, formación y los mecanismos educativos que harán realidad estas instancias "Integralistas".

\section{III. ¿Pedagogismo o educación en la edad preescolar?}

Si nos ubicamos en la posición opuesta a la señalada anteriormente, no hay duda que nos encontraremos frente a un "pedagogismo" o un "didactismo que se presenta como ajeno a las circunstancias socio-económicas que determinan al acceso de las personas a la educación formal del sistema. Es un hecho bastante comprobado el carácter discriminatorio de la educación en nuestros países y que pone en evidencia una situación claramente definida: la posibilidad de educarse está cerrada a las grandes mayorías. No es extraño entonces que "en los países Latinoamericanos la educación preescolar haya sido tradicionalmente una prerrogativa de los grupos sociales de mayores ingresos y un lujo distante e impracticable para la gran mayoría ${ }^{27}$.

Todos sabemos que para el aprendizaje deben existir algunos pre-requisitos, los cuales han sido establecidos como patrones pedagógicos en nuestros sistemas educativos. Se parte del supuesto que si no se dan estas condiciones en el niño, éste no va estar capacitado para integrarse a una actividad escolar que exige un desarrollo físico, intelectual, social y afectivo básico para adaptarse a esta nueva situación vital. La mayoría de las veces, las necesidades que debe satisfacer esta educación se centran en lo puramente individual, sin entrar a profundizar los factores socio-económicos que pueden determinarla. El proceso de enseñanza en nuestra sociedad, de facto, se plantea como un modelo standardizado que rige por igual para "todos", independientemente de la condición social de las personas que devengan los servicios educativos. Para algunos es un hecho natural, ya que la unidad y la coherencia del proceso educativo es la propia del sistema social donde actúa. Planteado en estos términos, hasta se podría justificar la naturaleza y la estructura de esta educación. Pero si somos honestos para juzgar esta realidad, nos veremos obligados a reconocer que esta educación actúa en una sociedad donde existen grupos dominantes y minoritarios que son los únicos beneficiarios de este sistema educativo. O sea los pre-requisitos mencionados, son determinados por las demandas de estos estratos sociales dominantes y obviamente por las condiciones de desarrollo del niño perteneciente a estos sectores. Si el carácter de un sistema educativo se encuentra determinado por las necesidades de esos grupos dominantes, es ingenuo pensar que la educación vaya a responder a las expectativas y demandas de los grupos mayoritarios de la población. Para que ello sea posible seria necesario eliminar las causas que promueven $y$ determinan este desequilibrio social. Desgraciadamente a este sistema educativo no le inquietan los factores que generan esta discriminación, ya que su misión es reproducir las coordenadas que le ha señalado el sistema social dominante.

Por otra parte, la pedagogía dominante, como teoría de la educación y ésta como práctica de la pedagogía, tienen como base de sustentación la institución escolar, que para la educación tradicional, es el eje y el pivote del proceso educativo. Para una familia, el envío de sus hijos al jardín infantil o a la escuela demanda costos de oportunidad, que en la mayoría de los casos no pueden sufragar, pero se esfuerzan por hacerlo, porque la propia dinámica discriminatoria del sistema le ha señalado el camino: comprar educación es comprar "status" social y económico o sea la vía para promoverse hacia niveles superiores. Pero estas variables no siempre actúan en el caso de la educación preescolar,

${ }^{27}$ Germani, Celia. 'Tradición y cambio en la Educación Preescolar Latinoamericana”. Revista Educación Hoy No. 22, Bogotá, 1974.

Digitalizado por RED ACADEMICA 
debido probablemente a su condición de no obligatoria y a la escasa inmediatez de sus beneficios sociales o pedagógicos. Para la mayoría, el jardín infantil puede representar una buena solución en el instante en que se necesite de un lugar para dejar los niños en las horas de trabajo, pero no siempre se acepta plenamente como un componente de la pirámide socio-educativa del sistema. Es útil, pero no necesaria, es la opinión de muchos sectores.

Ello nos demuestra que sobre el jardín no actúan numerosas variables socioeconómicas y culturales, que usualmente lo hacen en la escuela obligatoria. Los costos y gastos que demanda la atención de un niño preescolar, según afirman sus exegetas, es superior al de un niño escolar. Y a medida que aumentan los niveles de sofisticación de estos jardines infantiles, aumentan los gastos de personal especializado, de dotación, de infraestructura instalada, ayudas didácticas, movilización, etc., lo cual hace elevar las matrículas a niveles tales, que convierten estos centros en recintos muy exclusivos. Para los sectores populares, este elitismo convalida los argumentos que se esgrimen contra la educación preescolar en su conjunto y que se acepta como un lujo que muy pocos se pueden pagar. Para estos estratos sociales, aquello de "aprender a aprender" se convierte en un sofisma que solo tiene validez en las clases adineradas, ya que carece de la funcionalidad y de la utilidad de la escuela obligatoria, cuyos beneficios instruccionales se presentan como obvios. De ahí que no resulte extraño escuchar de labios de muchas personas pertenecientes a sectores populares y aún de los estratos medios, que el jardín infantil es un buen lugar para dejar a los niños, porque allí los cuidan, juegan, se divierten y "de paso", aprenden algunas cosas. Naturalmente las categorías "elitismo" y "educación" se truecan en instancias homólogas en este contexto preescolar. De ahí el menosprecio que existe por las funciones pedagógicas y educativas que cumple este tipo de educación. Los propios CAIP del ICBF, que descuidan el componente educacional, contribuyen a reforzar la condición elitista de la institución preescolar. El niño pobre irá al jardín infantil a alimentarse o en busca de un beneficio social, físico o afectivo inmediato, mientras que el niño rico, que ha satisfecho con creces estas necesidades básicas, podrá gozar de los beneficios educativos que le procuran los mecanismos de aprestamiento propios del jardín ${ }^{28}$.

El aceptar el jardín solo en el instante cuando se requiere de un servicio, que le garantice el cuidado y la atención de un niño, especialmente cuando la madre falta al hogar por razones socio-económicas, de ninguna manera inhabilitan o desvirtúan los propósitos educativos y sociales de un jardín preescolar. No olvidemos que en la actualidad, una de las funciones principales de estos centros es atender precisamente estas necesidades sociales. No podemos tampoco olvidar que la dura y difícil situación que enfrenta la familia de bajos ingresos, ha obligado a la mujer a salir de su hogar,

\footnotetext{
${ }^{28}$ No se conoce ningún estudio e investigación socio-económica sobre esta realidad. De los escasísimos trabajos que existen sobre el tema, nos encontramos con la muestra realizada por ICOLPE y ASCOFAME en 1970, a través de la cual se puede comprobar que el $74 \%$ de los niños de la muestra no asistieron al kinder o jardín. Estos resultados se entienden mejor si recordamos que la casi inexistente oferta de cursos preescolares oficiales implica que aquellos padres que deseen enviar su hijo a un kinder deberán remitirse, generalmente a colegios privados" (ICOLPE-ASCOFAME), Los escolares de los barrios populares de Bogotá: una reserva de talentos. Investigación: Educación, familia y salud'. Bogotá, 1974).

Uno de los filtros de selección son los gastos de matrícula, que en los jardines privados fluctúan entre 200 y 2000 pesos, según el establecimiento, que en la mayoría de los casos se amplían desorbitantemente debido a las exigencias de cuotas para el transporte, uniformes, reuniones o fiestas infantiles, lónchelas, materiales didácticos, etc. No es de extrañar esta situación, si se piensa que sólo en Bogotá, más del $50 \%$ de las mujeres y hombres poseen ingresos inferiores a los 1500 pesos mensuales. (DANE, "Encuesta Nacional de Hogares", Etapa 7, Bogotá, 1976).
} 
abandonar su proverbial función de madre e incorporarse al trabajo productivo con el propósito de ayudar al presupuesto familiar. Esta promoción de la mujer a instancias diferentes y solo aceptada a medias en estas últimas décadas, trajo como consecuencias, la emancipación de la mujer de las labores hogareñas, cambios en la crianza, cuidado y atención de los niños y naturalmente el surgimiento de numerosas instituciones especializadas en este campo. O sea numerosos factores socioeconómicos, culturales y pedagógicos se conjugaron para dar nacimiento a centros preescolares que buscaban paliar, ayudar o solucionar la difícil situación que afectaba a un sector mayoritario de la población.

Todo ello planteó numerosos interrogantes sobre los criterios que se debieran adoptar frente a un problema que no solo se reducía a instancias puramente educativas o pedagógicas, sino que tenía su respuesta en la naturaleza injusta y discriminatoria de la propia sociedad en donde se asienta este sistema educativo. Porque independientemente de las causas estructurales que generan estos problemas, no hay duda que los gobiernos de nuestros países se enfrentan a situaciones difíciles en el terreno de la planificación educativa, ya que en la medida que pasan los años y la educación preescolar crece con ritmo acelerado, las entidades oficiales han ido perdiendo el control de una realidad que ha terminado por escapársele de sus manos. Creemos que ello plantea una situación muy peligrosa para el futuro de la educación colombiana, ya que su desarrollo queda al arbitrio del azar o de los intereses mercantilistas y economicistas del sector privado, que al fin y al cabo son los sectores que dominan sin contrapeso la educación en Colombia.

\section{Algunos problemas que buscan solución}

Las orientaciones y las modalidades que hemos señalado con anterioridad, las hemos definido muy taxativamente, ya que en la práctica ellas no se presentan en forma clara. Esta ambigüedad de las posiciones en cuestión, ha dado margen para que surjan los argumentos $y$ las justificaciones de rigor en cada caso. $Y$ estas concepciones sobre la educación preescolar, de ninguna manera deben convertirse en palabras sueltas o juegos tentativos, sino sistemas estructurados y definidos, ya que de lo contrario seguiremos soportando una realidad que se ha transformado en un verdadero botín de la gran cantidad de instituciones e intereses que participan en la educación preescolar colombiana. De ahí que no resulte extraño, que ambas modalidades, la asistencialista o integral y la pedagógica posean una cobertura propia, institutos académicos que preparan docentes en preescolar con el propósito de satisfacer las demandas de un mercado ocupacional muy específico, instituciones privadas $u$ oficiales que las sustentan y las apoyan, y en fin, una infraestructura y una estructura institucional que ha reforzado aún más la división entre estos dos sectores.

La mayoría de los sectores educativos han reconocido que los logros materiales y en pequeña medida, las realizaciones sociales de la educación preescolar han sobrepasado con creces todos los criterios y orientaciones que tradicionalmente se ha señalado para estos sectores. Las acciones concretas en este terreno se han multiplicado a un ritmo acelerado, pero al margen de un orden coherente, de un desarrollo planificado o de un proceso orientado hacia metas más o menos definidas. Todo el mundo habla sobre la importancia que tiene la educación preescolar en la formación del niño, pero la mayoría de las veces no se sabe por qué, para qué y en qué dirección es importante. Por ejemplo, los médicos o los nutricionistas nos hablan de las consecuencias dramáticas que acarrea para el desarrollo intelectual y sicomotor del niño una malnutrición o una desnutrición avanzada; los sicólogos ponen énfasis en la necesidad de la estimulación afectiva en la formación intelectual del ser humano; los trabajadores sociales destacan la importancia 
que posee el ambiente familiar en la educación temprana; los maestros hacen un llamado de atención sobre las causas del fracaso y la deserción escolar, las cuales habría que buscarlas en las etapas de aprestamiento de los primeros años; los tecnólogos nos plantean la crisis de la educación preescolar como una crisis de medios y de métodos y proponen como solución unas sofisticadas líneas tecnológicas; los políticos del sistema sacan dividendos y explotan el drama de niño abandonado en beneficio de sus campañas proselitistas y de su imagen política, pero no les interesa comprometerse en acciones que ataquen las raíces del problema, porque el tema es siempre un inagotable manantial de ganancias políticas. Se hace referencia a los factores genéticos, biológicos, socioeconómicos, culturales, físicos o familiares, como determinantes en el crecimiento, diferenciación y desarrollo del niño preescolar. Desgraciadamente, toda esta pluralidad de criterios, solo ha contribuido a desorientar y a confundir a muchos sectores que perciben la educación preescolar como algo que existe, pero no saben concretamente lo que es. Se ha perdido la noción de la realidad, porque desde sus inicios esta área educativa, se ha desarrollado sin control, al margen de políticas y orientaciones definidas, sin planificación, independiente de los otros niveles educativos.

Como ya lo señalamos al comienzo, gran parte de esta anarquía y de esta confusión reinante, se debe a la carencia de una política coherente a nivel social que promueva, oriente, controle, defina y ponga en práctica todas aquellas iniciativas que hagan realidad los postulados que se han señalado para la educación integral del niño preescolar. Tampoco existe una legislación y un régimen jurídico que ponga control a un desarrollo indiscriminado y sin metas precisas, que al amparo de un mercantilismo desvergonzado, ha convertido esta área educativa en un negocio oneroso y lucrativo. Por otra parte, el clientelismo resultante de la multiplicidad de instituciones oficiales que dirigen, orientan, planifican y capacitan los diversos estamentos de la educación preescolar, ha derivado hacia la duplicidad de funciones, pugnas institucionales, extrema sectorización de sus programas y currículos. Los problemas son demasiados para tan poca respuesta, de ahí la necesidad de detenemos a analizar con mayor profundidad algunos de estos problemas. Muchos de ellos fueron señalados, debatidos y destacados en el Seminario de Centros Académicos para la formación del personal docente en preescolar y que organizó el Instituto Colombiano para el fomento de la educación superior ICFES en Bogotá el mes de agosto del presente año.

En Colombia, al Ministerio de Educación Nacional por ley le corresponde las funciones directrices en todo aquello que tenga relación con el Sistema Educativo Nacional. En el Decreto 088 de 1976, por el cual se reestructura el sistema educativo y se reorganiza esta entidad, por primera vez se incluyó la educación preescolar en los niveles progresivos de la educación formal y con ello se dejó de considerarla como una instancia aislada de la corriente principal de la educación en su totalidad. En este decreto se señalan las funciones de las diversas unidades administrativas y técnicas que les corresponde la misión de ejecutar y controlar la educación preescolar en su conjunto. Desafortunadamente por falta de recursos económicos, carencia de personal especializado, ausencia de una política clara y definida en este terreno, negligencia por parte de algunos directivos, etc., la mayoría de estas funciones no se cumplen y ellas, de facto, las han venido cumpliendo otras instituciones, sin el asesoramiento y control del organismo ministerial. Por ejemplo, el ICBF ha estatuido y puesto en práctica todo un programa de capacitación y formación para los docentes en preescolar que se van a desempeñar como maestras de los CAIP. Y aunque en el Artículo 33 del mencionado Decreto 088 se señala que la División de Diseño y Programación Curricular de Educación Formal debe "diseñar y elaborar el currículo de la educación preescolar, en colaboración del ICBF", de hecho estas recomendaciones no se cumplen, ya que el ICBF actúa con 
plena independencia en este terreno. No es de extrañar esta situación, ya que en el Consejo de Administración del Plan Nacional de Centros de Atención Integral al Preescolar, el Ministerio de Educación u otras entidades educativas, no tienen ninguna representación.

A pesar de que a la División de Educación Preescolar y Educación Especial del Ministerio de Educación le corresponde las funciones de programar, asesorar, inspeccionar, fomentar y cooperar en todo aquello que atañe y se relacione con esta área educativa, tampoco esta dependencia oficial ha tenido mayor ingerencia en los programas de formación docente y de capacitación realizados por el ICBF, cuya autonomía técnica, pedagógica y financiera en este terreno es casi total. Si a ello sumamos las políticas y los programas que adelantan las secretarías departamentales, intendenciales y comisariales de educación en diversas ciudades del país, deduciremos que los niveles de dispersión y de disgregación son aún mayores. Por otra parte, las universidades y academias privadas organizan y ponen en práctica sus propios programas curriculares, sin el debido control y asesoramiento del Ministerio de Educación, a excepción del ICFES, que lleva a cabo un conveniente control de los programas preescolares que debe aprobar e inspeccionar a nivel universitario. Como se puede observar la situación es confusa y compleja, lo cual ha impedido tener una visión panorámica y total de la realidad preescolar, que crece día a día, al margen e independiente del control oficial.

Tampoco se trata de plantearse como solución definitiva y radical la implantación de un patrón único nacional, ya que no existen las condiciones objetivas y subjetivas que posibiliten tales medidas. Colombia es un país con necesidades y características diferentes, con una geografía accidentada y comunidades o regiones con marcadas diferencias culturales, climatéricas y socioeconómicas, lo cual hace difícil poner en práctica programas únicos. Pero si no se puede alcanzar cierta unidad por estas vías, en cambio se debe pensar seriamente en lograr esta coherencia alrededor de ciertos postulados educativos y socio-económicos básicos. Ello se logrará solo en el instante en que los organismos sectores de la educación preescolar en el país, el Ministerio de Educación, el ICFES, el ICBF y las universidades oficiales y privadas, participen en una acción común y solidaria, destinada a conjugar sus recursos económicos, personal técnico, experiencia y todo aquello que puede contribuir a conjugar estos recursos materiales y humanos.

Aunque muchos aspiran alcanzar estas metas por la vía burocrática o administrativa, el estudio de la realidad preescolar en Colombia ha posibilitado comprender que la solución no siempre se puede alcanzar a través de un formulismo que remite el problema a los niveles de un mecanismo burocrático, sin bases teóricas y conceptuales que lo sustenten. En la actualidad se suman decretos y resoluciones que no corresponden a las necesidades y a las exigencias que requiere una realidad preescolar que se desarrolla sin un rumbo y un propósito definido.

Muchas universidades e institutos de educación superior que poseen en sus regímenes académicos la especialidad preescolar, se encuentran confusos y desconcertados frente a la falta de definición de los niveles académicos que deben existir o deben tener preeminencia en la educación preescolar. No se podría afirmar perentoriamente que tal o cual nivel deben ser los definitivos, ya que ello implicaría o exigiría un estudio más a fondo sobre esta realidad. Pero cuando se decida, no hay que olvidar que el referente debe ser necesariamente el proceso educativo en su totalidad, ya que de lo contrario la educación preescolar se convertiría en una entidad autónoma e independiente de los niveles de la educación formal. 
Precisamente, a propósito de las soluciones planteadas por algunas instituciones oficiales, se ha venido insistiendo en la necesidad de encuadrar la educación preescolar dentro de los criterios y los diseños propios de la tecnología educativa, cuyos planteamientos metodológicos han tenido como centro la Dirección General de Capacitación y Perfeccionamiento Docente, Currículo y Medios Educativos a través de su División de Medios de Educación a Distancia y la División de Educación Tecnológica del ICFES. Nadie niega la importancia que posee en la actualidad los medios tecnológicos, pero creemos que no está exenta de cierta irresponsabilidad la posición asumida por estos tecnólogos frente al área preescolar, ya que en sus argumentos no se contemplan las bases, los fundamentos y las premisas básicas de este nivel educativo, los cuales se reducen a unos esquemas operacionales de dudosa vigencia. La problemática preescolar se reduce a un conjunto de factores ambiguos, amorfos y que reflejan la poca claridad que existe sobre la tecnología educacional, tecnología de la enseñanza o tecnología de la educación, cuya pluralidad de definiciones confunde a los que leen o escuchan exposiciones sobre el tema y que frustran su capacidad, tanto para comprender como para evaluar la educación preescolar. Señalamos este hecho, porque creemos que los procedimientos, métodos y teorías que sustentan esta tecnología educativa tienen como referencia principal el proceso de enseñanza-aprendizaje, que en la educación preescolar se plantea en términos de aprestamiento o de pre-enseñanza. $Y$ a pesar de los grandes esfuerzos que realizan sus exegetas para demostrar lo contrario, la tecnología educativa se encuentra enmarcada en una línea básicamente cognoscitivista e instruccional o sea la transferencia de conocimientos, que en la educación preescolar es solo un instrumento para lograr o alcanzar determinados fines dentro de este proceso de aprestamiento, pero de ninguna manera es su propósito central. De ahí que las áreas sicomotoras, socioafectivas y los valores de la creatividad sean para los tecnólogos, apéndices secundarios del proceso de enseñanza. No es extraño entonces que uno de los teóricos de esta tecnología educativa y uno de los creadores de la teoría del condicionamiento instrumental u operante, B.F. Skinner, haya ironizado una pedagogía así orientada: "los esfuerzos por educar la creatividad han sacrificado la enseñanza de contenidos de materias “29

Y aunque no negamos los beneficios que ha procurado la tecnología al sistema instruccional, especialmente en materia de medios técnicos y en el diseño metodológico, no hay duda que sus concepciones no logran sacudir-se de esa línea mecanicista que solo le interesa valorar los resultados o los productos del aprendizaje y no los procesos cognitivos, intelectuales o socio-afectivos que se desarrollan en el proceso de enseñanza o de formación, que son al fin y al cabo las premisas básicas del currículo y de la actividad preescolar. Además los intereses económicos e ideológicos que giran en torno de la tecnología educativa, nos ponen de manifiesto, que detrás de todo esto se encuentra la presencia de las grandes transnacionales y monopolios que controlan la producción y la venta de esta tecnología. Sería conveniente abrir un debate y una discusión científica sobre el tema, ya que los estrechos limites de este trabajo nos impiden profundizar un hecho que se ha convertido en factor de numerosas controversias. Porque las críticas han venido creciendo en los sectores educativos, en la medida que los tecnólogos han ido ocupando cargos y posiciones fundamentales en el aparato educativo del sistema y han planteado la "tecnocratización" de la educación, como si el concepto "tecnología educativa" fuera un fin en si mismo o un mecanismo que va solucionar todos los problemas de la educación. James Armsey y Norman Dahl afirman que "a pesar de los fuertes sentimientos en favor y en contra que suscita la tecnología educativa y su creciente prominencia, el campo está plagado de definiciones vagas, propósitos nebulo-

\footnotetext{
${ }^{29}$ Skinner, B.F. Tecnología de la enseñanza, Ed. Labor, Madrid, 1970.

Digitalizado por RED ACADEMICA
} 
sos y evaluaciones sombrías. Esto es producto de un conjunto de factores: interpretaciones diferentes acerca de qué lo que constituye el campo mismo; objetivos confusos y en conflicto; excesiva acentuación de la tecnología por sí misma; demasiadas promesas infladas de las personas que se ocupan del equipo físico; escasa atención a la calidad de los programas y los materiales; resistencia encubierta, manifiesta y permanente por parte del sistema educacional tradicional; falta de rigor y especificidad en la investigación; incapacidad para efectuar las demostraciones, y una resistencia a emplear la tecnología en "de" y "no" como una adición a lo que se está haciendo actualmente" 30 .

Otro asunto que parece inquietar a los pedagogos, es sin lugar a dudas el acentuado mercantilismo que se observa en la educación preescolar privada, que ha convertido esta área educativa en un próspero y lucrativo negocio que ha sabido explotar inteligentemente las necesidades socio-económicas y culturales de los medios familiares, que por un imperativo social o económico se ha visto obligada a dejar sus hijos en instituciones "especializadas" para el cuidado y atención del niño en edad preescolar. En estos últimos años, se ha podido observar en Colombia y especialmente en Bogotá, una extrema y peligrosa proliferación de jardines infantiles y guarderías, la mayoría de las cuales no reúnen las condiciones locativas mínimas para su funcionamiento, que poseen un bajísimo nivel pedagógico como consecuencia de un personal docente poco idóneo para desempeñarse y que en general, lucran a costa de las necesidades de muchos padres de familia, que a menudo son engañados por los mecanismos publicitarios que ofrecen servicios que en la práctica no se cumplen.

En Bogotá, aproximadamente el $60 \%$ de los jardines privados carecen de licencia de funcionamiento o sea no cuentan con la aprobación de los organismos que tienen la responsabilidad de controlar y súper vigilar estos centros. $O$ sea de hecho son jardines ilegales, que usualmente matriculan niños, publican avisos en los periódicos y cumplen normalmente sus actividades, sin que medie ninguna limitación jurídica o legal. En el papel existe una legislación sobre las condiciones mínimas que deben reunir estos centros preescolares para su funcionamiento, pero en la práctica no se cumplen estas normas, situación que ha contribuido a desacreditar la imagen pedagógica de la educación preescolar. Todo ello contribuye a alimentar la desconfianza entre los grupos familiares que utilizan sus servicios y que a la larga han convertido la institución preescolar en una improvisada e imprecisa fórmula que malamente busca resolver una emergencia social determinada y en un negocio que produce buenas ganancias a sus educadores-empresarios.

En el Seminario Nacional de Centros Académicos organizado por el ICFES en el mes de agosto en Bogotá, se pudo comprobar que una de las fallas fundamentales que atentan contra su desarrollo, es el menosprecio que existe entre las instituciones oficiales por las condiciones subjetivas que deben darse como condición previa antes de llevar a la práctica todas aquellas acciones destinadas a crear y a poner en funcionamiento un jardín infantil, un CAIP o una guardería, Se parte de la premisa de una intención a priori", que plantea una supuesta aceptación por parte de la comunidad de los servicios procurados. Con ello, no queremos señalar que una comunidad vaya a rechazar algo que se le da y se le ofrece gratuitamente, sino que no existen los suficientes niveles de conciencia frente a la necesidades que implica la existencia de una entidad preescolar.

\footnotetext{
${ }^{30}$ Armsey, J. y Dahl, N. Tecnología de la enseñanza, Ed. Guadalupe, Buenos Aires, 1975.
} 
Puede suceder que a una comunidad le dé igual que exista o no un jardín, debido precisamente a la falta de claridad sobre los propósitos de la educación preescolar y a los derechos que tiene esa comunidad a disfrutar de los beneficios de esos servicios. De ahí que los jardines o los CAIP creados en barrios populares aparecen como impuestos "desde arriba" y no como una respuesta a las necesidades'que se generan "desde abajo". No es extraño entonces que se produzcan diversas instancias de resistencia o de oposición por parte de muchos grupos familiares, salvo que medie una necesidad socioeconómica que debe satisfacer en forma inmediata, no siempre se acepta que una institución oficie de sustituto de la madre, el padre o el hogar. Aunque muchas veces, la existencia de un jardín infantil en un sector de bajos ingresos, por presencia puede ayudar a crear conciencia en la comunidad sobre los méritos de estas instituciones, en la mayoría de los casos, la fundación masiva de jardines no va generar automáticamente un estado de conciencia en la comunidad sobre las proyecciones futuras, los beneficios mediatos 0 sobre los méritos educativos de estos servicios. El problema no está en la oferta, ya que un aumento apreciable de jardines no va a solucionar el problema fundamental, debido a las numerosas variables socio-económicas y culturales que actúan en estos casos y que muchas veces impiden, que la demanda por educación sea mayor. Esto que parece un contrasentido, se explica por las raíces profundas de un problema, que remite a una estructura educativa generada sobre la imposibilidad objetiva, que tiene el pueblo de demandar educación y de exigir en términos de derecho inalienable.

Aquí se reedita el mismo fenómeno que se observa en el caso de la educación de adultos y la alfabetización: si el aprender a leer y escribir no se convierte en un mecanismo que ayude positivamente a superar al pueblo, su condición de atraso y de hecho no se transforma en un derecho que le corresponde exigir a las clases gubernamentales, cualquier acción educativa que se procure en este sentido, siempre será recibida como un mecanismo de imposición, que los beneficiarios aceptarán porque ello le procura un beneficio inmediato. De esta forma, todos estos servicios se convierten en un "regalo" o en un acto magnánimo del sistema y no un derecho que los miembros de una comunidad pueden exigir cuando estos servicios no existen o cuando ellos no cumplan las funciones para los cuales han sido creados.

Solo silos padres logran comprender y tomar conciencia que la educación preescolar es una prerrogativa que pueden exigir y que les corresponde por un imperativo social, se logrará el apoyo y la ayuda de todos aquellos sectores sociales que de una u otra forma se benefician con sus servicios. Y aunque el ICBF se ha planteado en sus programas una extensión familiar de sus servicios, desafortunadamente los patrones y las acciones que se han puesto en práctica con tal propósito, no han hecho otra cosa que reforzar esta naturaleza impositiva del servicio. No es extraño entonces, que se presenten situaciones absurdas como consecuencia de esta falta de claridad sobre los beneficios y roles que debe desempeñar la educación preescolar en la comunidad. Por ejemplo, en muchos CAIP departamentales han quedado cupos vacantes, ya que por ignorancia, prejuicios o falta de información de los padres no ha sido posible llenar estos cupos, a pesar del dramático déficit que existe en Colombia en este terreno. Muchas veces los funcionarios del ICBF se han quejado de la falta de colaboración y de apoyo de la comunidad para sacar adelante algunos proyectos, pero ellos no han previsto las condiciones básicas que deben prevalecer antes de fundar un CAIP. Cuando los consumidores potenciales de estos servicios (grupos familiares, sindicatos, asociaciones sociales y culturales, centros laborales, etc.) tomen conciencia de los derechos que les corresponde en cada caso, ellos mismos ejercerán el control de estos servicios y podrán exigir una justicia social que de hecho se le ha negado a los sectores marginados del sistema educacional. 
Si bien, en los programas vigentes se recomienda integrar horizontalmente los servicios preescolares y la educación preescolar ha sido incluida legalmente en los niveles progresivos de la educación formal, en la práctica esta área educativa se considera aislada del proceso de educación total. Debido probablemente a prejuicios, a ignorancia o a falta de claridad de las autoridades educativas y a las propias limitaciones del sistema educativo oficial, se ha llegado hasta el extremo de oponer la educación preescolar a la escuela obligatoria, como si ambos niveles no fueran de un tronco básico y común. Gastón Mialaret afirma que "a veces, la educación preescolar, para conservar su autonomía y sus métodos pedagógicos y originales, se ha sentido impulsada a cerrarse en sí misma y, en ciertos casos, a oponerse a la escuela primaria, cuando en realidad se hubiera podido establecer fácilmente una vinculación orgánica entre ellas. A la escuela obligatoria, que se caracteriza todavía con harta frecuencia por su rigidez y su tradicionalismo pedagógico, la educación preescolar opone una pedagogía más moderna, mejor adaptada a las necesidades del niño y abierta a las corrientes pedagógicas contemporáneas. En tal caso, la escuela primaria asimila difícilmente a esos alumnos acostumbrados a una cierta libertad, curiosos e interesados por lo que no siempre es el tema de enseñanza que se les propone"31.

No podemos negarlo, el problema es real y se hace más crítico en el instante en que el niño hace su entrada a la escuela y presenta dificultades sicológicas en su etapa de adaptación al régimen escolar e incluso se perciben traumatismos como consecuencia de los ajustes que debe hacer el niño frente a esta nueva situación. Los conceptos "aprestamiento" y "educación escolar" se han convertido en la práctica en instancias casi antagónicas, debido a numerosos factores y causas de índole institucional, pedagógicas y socioeconómicas. Cada área educativa posee su propio cuerpo de educadores, sus propios programas curriculares, sus propios locales, su propia estructura institucional, la cual, muchas veces no contempla el "antes" ni el "después" del proceso educativo que les corresponde implementar. Probablemente si se realizaran estudios longitudinales o de seguimiento, desde que el niño se incorpora al jardín infantil hasta la culminación del período escolar, se descubrirían más fácilmente las fallas que afectan este proceso educativo discontinuo.

Facilitar el paso del jardín a la escuela obligatoria debiera ser el propósito de la educación preescolar, pero desafortunadamente en la escuela no se considera, con la seriedad que merece, la etapa de aprestamiento. Aunque algunos establecimientos recomiendan a los niños que recién se incorporan al ciclo escolar, su paso por el jardín, en general no existe como prerrequisito establecido, debido fundamentalmente al carácter no obligatorio de la educación preescolar. En algunos casos, cuando se ha buscado la solución por la vía del reentrenamiento del maestro primario para que ejerza también en el jardín, se ha observado una tendencia hacia la escolarización de la educación preescolar. La imposibilidad de que los educadores pertenezcan a uno y otro nivel, ha contribuido a crear un obstáculo, que a los niños les cuesta salvar. Muchos de estos problemas derivados de la falta de integración o de continuidad entre la educación preescolar y la escolar, son conocidos y son aceptados por los docentes y las autoridades educativas, pero no han hecho nada al respecto para solucionamos. ¿Son tan fuertes tos intereses personales e institucionales, como para imposibilitar la fórmula que permita solucionar estos problemas? Probablemente pregunta muy ingenua para una realidad, cuya problemática continúa siendo tan marginal como cualquier problema que tenga relación con el niño colombiano.

\footnotetext{
${ }^{31}$ Gastón Mialaret, La educación preescolar en el mundo (UNESCO: 1976). Digitalizado por RED ACADEMICA
} 


\section{BIBLIOGRAFIA}

\section{Nota:}

Aunque muchas de las fuentes bibliográficas que se señalan a continuación han servido para fundamentar y estructurar este trabajo, en gran medida los conceptos e ideas desarrolladas han surgido como resultado de algunas experiencias y trabajos específicos del autor.

CERDA, Hugo y López, Absalón, La Educación Preescolar en Colombia: mito o realidad. ICFES, Bogotá, 1978.

FUNDACION VAN LEER, Misión sobre educación infantil temprana, Informe, La Haya, 1976.

MIALARET, Gastón, La Educación Preescolar en el Mundo, UNESCO, 1976.

TIZARD, Jack, Revista Salud Mundial, No. 15. OMS, 1974.

GERMANI, Celia. Revista Educación Hoy, No. 22. "Tradición y cambio en la Educación Preescolar Latinoamericana". Bogotá, 1974.

SKINNER. B.F., Tecnología de la Enseñanza, Ed. Labor. Barcelona, 1970.

DANE, Boletín Mensual de Estadística. "La Educación en Colombia”, Bogotá, 1977.

DANE, Directorio de Establecimientos Educativos, Preescolar, Primaria y Secundaria, Bogotá, 1974.

UNIVERSIDAD PEDAGOGICA NACIONAL, Documentación Educativa, No. 9, Vol. 3, Enero-Febrero, Bogotá, 1976.

ICBF, Centros de Atención Integral al Preescolar, Modelos, Bogotá, 1976.

ICBF, Informe Proyectos CAIP, Noviembre 1975, Bogotá.

MINISTERIO DE EDUCACION, Programa Nacional de Mejoramiento Cualitativo de la Educación, División de Radio y TV Educativas, Bogotá, septiembre 1975.

MARTINEZ, Alicia y otros autores, ¿Qué es una guardería infantil? Ed. Trillas, México, 1972.

ARMSEY, J. y DAHL, N. Tecnología de la Enseñanza. Ed. Guadalupe, Buenos Aires. 1975. 